\title{
Response to a letter to the editor concerning "Giant Cell Reparative Granuloma of the Scapula: report of a case and literature review"
}

\author{
Andrea Angelini ${ }^{1} \cdot$ Pietro Ruggieri $^{1}$
}

Published online: 23 October 2019

(C) ISS 2019

We read with interest the letter to the editor regarding our manuscript on giant cell reparative granuloma (GCRG) of the scapula. The author commented that some relevant aspects have been omitted in the description and discussion of the case, making the paper unclear for readers.

It assumes the possibility that our case should be considered a solid form of aneurysmal bone cyst (s-ABC). Bertoni et al. [1], Oda et al. [2], and Ilaslan et al. [3] reported lesions with similar morphology in the long bones and designated them as solid ABC or extragnathic GCRG. To the best of our knowledge and based on the recent published literature, these two entities have been included in the group of giant cell lesions of bone. No clear criteria have been identified to distinguish the GCRG that occurred in the extremities (not in gnathic area or in small bones of the hands and feet) with s-ABC. The importance of recent discovery about USP6 mutations in ABC, GCRG, and other entities has not been omitted. In fact, $\mathrm{ABC}$ is now widely accepted as a neoplasm owing to recent findings of recurrent clonal chromosomal alterations. USP6 (also called TRE17/ ubiquitin-specific protease 6) is a deubiquitinase that is involved in the arrest of maturation of the osteoblasts. The related gene is localized to the short arm of chromosome 17 (17p13). The result of the chromosomal anomaly is a hybrid gene, mostly identified as $\mathrm{t}(16 ; 17)(\mathrm{q} 22 ; \mathrm{p} 13) \mathrm{CDH} 11 / \mathrm{USP} 6$. As we previously reported, genetic abnormalities of chromosome 17 have been widely described in s-ABC or GCRG, even if other infrequent chromosomal rearrangements have also been reported [4]. The solid variant of $\mathrm{ABC}$ has been shown to harbor similar genetic events as the classic cystic lesions, as well in GCRG of the extremities [5]. Based on genetic evaluation, Agaram et al recommended that only the terminology of GCRG of the hands

Andrea Angelini

andrea.angelini83@yahoo.it

1 Department of Orthopedics and Orthopedic Oncology, University of Padova, Via Giustiniani 3, Padova, Italy and feet should be abandoned and replaced instead with either $\mathrm{ABC}$ or solid variant of $\mathrm{ABC}$ depending on the radiologic findings [5]. The USP6 rearrangement on FISH, if present, can distinguish s-ABC/GCRG from other lesions with secondary $\mathrm{ABC}$ formation, metastases, or brown tumors [6]. In our case, we did not perform the FISH analysis to find rearrangements of the USP6 gene.

As stated in our original manuscript, this entity has a wide range of clinical and radiographic presentation and requires adequate staging and biopsy to avoid diagnostic errors and potential mismanagement. Evaluation of UPS6 mutations could help in further histologic definition, even if up to $80 \%$ of both s-ABC and GCRG cases with genetic abnormalities reported in literature have shown some alteration of chromosome 17 [4].

\section{References}

1. Bertoni F, Bacchini P, Capanna R, Ruggieri P, Biagini R, Ferruzzi A, et al. Solid variant of aneurysmal bone cyst. Cancer. 1993;71:72934.

2. Oda Y, Tsuneyoshi M, Shinohara N. "Solid" variant of aneurysmal bone cyst (extragnathic giant cell reparative granuloma) in the axial skeleton and long bones. A study of its morphologic spectrum and distinction from allied giant cell lesions. Cancer. 1992;70:2642-9.

3. Ilaslan H, Sundaram M, Unni KK. Solid variant of aneurysmal bone cysts in long tubular bones: giant cell reparative granuloma. AJR Am J Roentgenol. 2003;180:1681-7.

4. Pan Z, Sanger WG, Bridge JA, Hunter WJ, Siegal GP, Wei S. A novel $\mathrm{t}(6 ; 13)(\mathrm{q} 15 ; \mathrm{q} 34)$ translocation in a giant cell reparative granuloma (solid aneurysmal bone cyst). Hum Pathol. 2012;43(6):952-7.

5. Agaram NP, LeLoarer FV, Zhang L, Hwang S, Athanasian EA, Hameed M, et al. USP6 gene rearrangements occur preferentially in giant cell reparative granulomas of the hands and feet but not in gnathic location. Hum Pathol. 2014;45(6):1147-52.

6. Matcuk GR Jr, Chopra S, Menendez LR. Solid aneurysmal bone cyst of the humerus mimics metastasis or brown tumor. Clin Imaging. 2018;52:117-22 S Fiona Bonar, only author.

Publisher's note Springer Nature remains neutral with regard to jurisdictional claims in published maps and institutional affiliations. 